\title{
INTEGRATING IMAGE AT DIFFERENT SPATIAL RESOLUTIONS AND FIELD DATA FOR SEAGRASS PERCENT COVER MAPPING
}

\author{
P. Wicaksono ${ }^{1, *}$, W. Lazuardi ${ }^{2}$, M. Munir ${ }^{3}$ \\ ${ }^{1}$ Department of Geographic Information Science, Faculty of Geography, Universitas Gadjah Mada, Yogyakarta, Indonesia 55281 - \\ prama.wicaksono@ugm.ac.id \\ ${ }^{2}$ MPPDAS, Faculty of Geography, Universitas Gadjah Mada, Yogyakarta, Indonesia 55281 - wahyulazuardi35@ gmail.com \\ ${ }^{3}$ Cartography and Remote Sensing, Faculty of Geography, Universitas Gadjah Mada, Yogyakarta, Indonesia 55281 - \\ miftakhul.munir@mail.ugm.ac.id
}

\section{Commission IV}

KEY WORDS: Seagrass, Percent Cover, Mapping, Spatial Resolution, WorldView-2, PlanetScope

\begin{abstract}
:
There are not many discussion or previous works that specifically address the issue of integrating small field plot size $\left(1 \mathrm{~m}^{2}\right)$ and image at different spatial resolutions in the seagrass percent cover (PC) mapping using remote sensing. This is important to determine the spatial resolution of image that can still be effectively integrated with $1 \times 1 \mathrm{~m}$ plot size field data. This research aimed at assessing the accuracy and spatial distribution of seagrass PC map modelled from image at different spatial resolutions, using seagrass field data measure at $1 \mathrm{~m}^{2}$ plot size. Two multispectral satellite images namely WorldView-2 (2m) and PlanetScope (3m) were used for this research and simulated to $5 \mathrm{~m}, 10 \mathrm{~m}, 15 \mathrm{~m}$, and $30 \mathrm{~m}$. Kemujan and Lombok Island were selected as the study area, and seagrass beds in each island have different characteristics. Machine learning random forest regression was used to perform empirical modelling and the mapping accuracy was assessed using independent seagrass PC samples. The results indicated that $1 \mathrm{~m}^{2}$ plot size is still effective to be integrated with image up to $30 \mathrm{~m}$ spatial resolution, where the RMSE and overall seagrass PC pattern is relatively similar but the level of information precision is reduced at lower spatial resolution. Furthermore, we found out that the main factor that strongly determines the success use of $1 \mathrm{~m}^{2}$ plot size and the mapping accuracy is the configuration of the seagrass bed in the study area. Seagrass PC in the more continuous seagrass bed can be mapped with higher accuracy than in patchy seagrass bed.
\end{abstract}

\section{INTRODUCTION}

Seagrass is a marine angiosperm living in a coastal area that provide many ecosystem services to their and the surroundings ecosystems, which includes providing food for marine biotas, water purification, sediment stabilizer, shelter and nursery ground for juvenile and adult marine biotas, coastal protection from storm and erosion, alternative food for human and cattle, fertilizer, carbon sink, and aesthetic values for the adjacent coastal communities (Nordlund et al. 2016). Due to these services, seagrass is considered to be more valuable than mangrove and coral reef with 19,990 USD per hectare per year of economic value (Costanza et al. 1997). Therefore, understanding their spatial distribution and abundance is very important to ensure their sustainability, the availability of seagrass abundance map is very beneficial to assist coastal manager in designing a proper management effort to manage their coastal areas.

The understanding of the spatial distribution of seagrass becomes even more important due to the fact that seagrass coverage is declining worldwide (Waycott et al. 2009). Indonesia, which is located in the Coral Triangle Initiative (CTI) region, shelter a high biodiversity of Indo-Pacific seagrass species. Unfortunately, map showing their spatial distribution and abundance is currently lacking.

Common approach for seagrass mapping is by integrating remote sensing and seagrass information collecting in the field using empirical model, by involving radiometrically corrected bands, and or index development, band ratio, and image transformation (Phinn et al. 2008; Lyons et al. 2013; Wicaksono, Hafizt, 2013; Roelfsema et al. 2014). Several seagrass biophysical properties that has been successfully mapped using remote sensing are species composition, percent cover, leaf area index (LAI), biomass, and above ground carbon stock (Hossain et al. 2015; Wicaksono et al. 2019a). Each of these properties provide different insight onto seagrass role in the coastal ecosystem, and according to McKenzie et al. (2001), seagrass percent cover is the key parameter for seagrass monitoring effort. Seagrass percent cover can be defined as the percentage of area covered by seagrass per unit area. Commonly used size to measure seagrass percent cover is $1 \times 1 \mathrm{~m}$ or $0.5 \times$ $0.5 \mathrm{~m}$, and the percent cover represent the ratio of seagrass coverage within that $1 \mathrm{~m}^{2}$ or $0.25 \mathrm{~m}^{2}$. This percent cover value is then used to train the model to obtain the resultant regression function that can be used to upscale the seagrass information at plot level measurement to the landscape level measurement.

The issue of this approach is the difference between plot size and image spatial resolution. There will be discrepancy in the information collected in the field and the reflectance of the pixel due to coverage area difference. Ideally, the plot size should be close to the size of the remote sensing image pixel size, if not similar or even larger to accommodate the spatial displacement in both field data and image coordinate. In case of seagrass and supposedly other benthic habitats, it will be very difficult and almost impossible to follow this practice since there are issues regarding the accessibility, resources and challenges in collecting field data. Thus, so far, remote sensing application for seagrass percent cover mapping utilizing image at different spatial resolutions used information collected from similar field seagrass plot size, either at $1 \mathrm{~m}^{2}$ or $0.25 \mathrm{~m}^{2}$. While many previous seagrass mapping efforts were successful despite this issue, it is still necessary to assess if there is any trade-off by using small plot size to train image at different spatial

\footnotetext{
* Corresponding author
} 
resolutions, in term of the accuracy and the spatial distribution of seagrass abundance in the resulting map.

This research aimed at assessing the accuracy and spatial distribution of seagrass percent cover map (hereafter called seagrass PC) modelled from image at different spatial resolutions using seagrass field data measure at $1 \mathrm{~m}^{2}$ plot size. Two multispectral satellite images namely WorldView-2 (2m) and PlanetScope $(3 \mathrm{~m})$ were used for this research. The spatial resolution of these images was also resampled to $5 \mathrm{~m}, 10 \mathrm{~m}$, $15 \mathrm{~m}$, and $30 \mathrm{~m}$ to simulate the spatial resolution of widely available satellite images in the market, i.e., SPOT, Sentinel-2, ASTER VNIR, Landsat. Two study areas were selected that represent different seagrass landscape. The first study area is Kemujan Island. Seagrass in this island is fringing narrowly along the shoreline and highly mixed with macroalgae, carbonate sand, and reddish-coloured volcanic sand, as well as live and dead coral. The second study area is in the southern coast of Lombok Island. In this area, the seagrass bed is wider and more clustered with less mixing with other benthic habitats. WorldView-2 image was selected for Kemujan Island due to its seagrass patchy characteristic that requires higher spatial resolution and PlanetScope was used for Lombok Island since seagrass in this area is wider and more clustered. The use of two images and study areas with different characteristic was necessary as a control to avoid bias in the conclusion due to image quality and seagrass landscape variations. In addition, since this research involve data at different measurement sizes (image pixel size, resampled pixel, and field plot size), it is also critical to assess if the result is affected by the composition and complexity of the seagrass bed. We argue that the successful use of $1 \mathrm{~m}^{2}$ plot size to train image at different resolution is subject to the condition of seagrass bed (patchy or clustered). Pixel mixing at lower spatial resolution image in patchy seagrass bed is higher than in clustered seagrass bed, and this strongly influence the feasibility of using $1 \mathrm{~m}^{2}$ plot size to train the remote sensing image.

\section{STUDY AREA}

Kemujan Island is the second biggest island in Karimunjawa Islands. This island has a good benthic habitat geomorphic variation, which include reef flat, shallow lagoon, back reef, reef crest, fore reef, and escarpment. Seagrass beds are mainly located in the narrow reef flat along the shoreline mixed with brown algae, rubble, and dead coral. Seagrass beds in this island are rarely found in a continuous and clustered configuration, and thus poses challenge for mapping effort. In contrast, seagrass bed in the southern parts of Lombok Island is more continuous and clustered. Seagrass beds are mostly located in the wide and shallow reef flat with sand and rubble substrate. Seagrass in both areas are commonly located at the depth less than $2 \mathrm{~m}$. The location of the study area can be seen in Figure 1 .

\section{METHODS}

\subsection{Image data}

The WorldView-2 image of Kemujan Island was recorded on 24 May 2012, obtained at LV3X and has been orthorectified. Therefore, no further geometric correction is necessary. However, atmospheric correction was still necessary. It has 6 visible bands and 2 near infrared bands and a spatial resolution of $2 \mathrm{~m}$. The image was acquired slightly off-nadir and thus the spatial resolution is $2 \mathrm{~m}$ instead of $1.84 \mathrm{~m}$. The PlanetScope image of Lombok Island was recorded on 2 August 2018. It was an SR (surface reflectance) orthorectified product, where geometric and atmospheric correction has been applied. The spatial resolution is $3 \mathrm{~m}$ and it has 3 visible bands and 1 near infrared band.

\subsection{Image preparation}

Before further processing, atmospheric correction and sunglint correction were applied to WorldView-2 image. Dark Object Subtraction (DOS) method using optically deep water pixels free from sunglint was used to calculate the atmospheric offset and used to remove atmospheric effect from WorldView-2 image (Wicaksono, Hafizt, 2018). Sunglint correction using Hedley et al. (2005) method was then applied to the atmospherically-corrected WorldView-2 image since sunglint is visible in the optically shallow water above seagrass bed. In short, the empirical relationship between visible and near infrared bands was used to predict the magnitude of sunglint noise in the visible band and minimize the sunglint in visible bands. Since there are two near infrared bands for WorldView2 , the empirical relationship was assessed for both near infrared bands to determine the most suitable infrared band to help remove sunglint in particular visible band. There was no further correction for PlanetScope SR image as the sunglint is not affecting the seagrass bed. Afterward, land and optically-deep water pixels in both images were masked out.
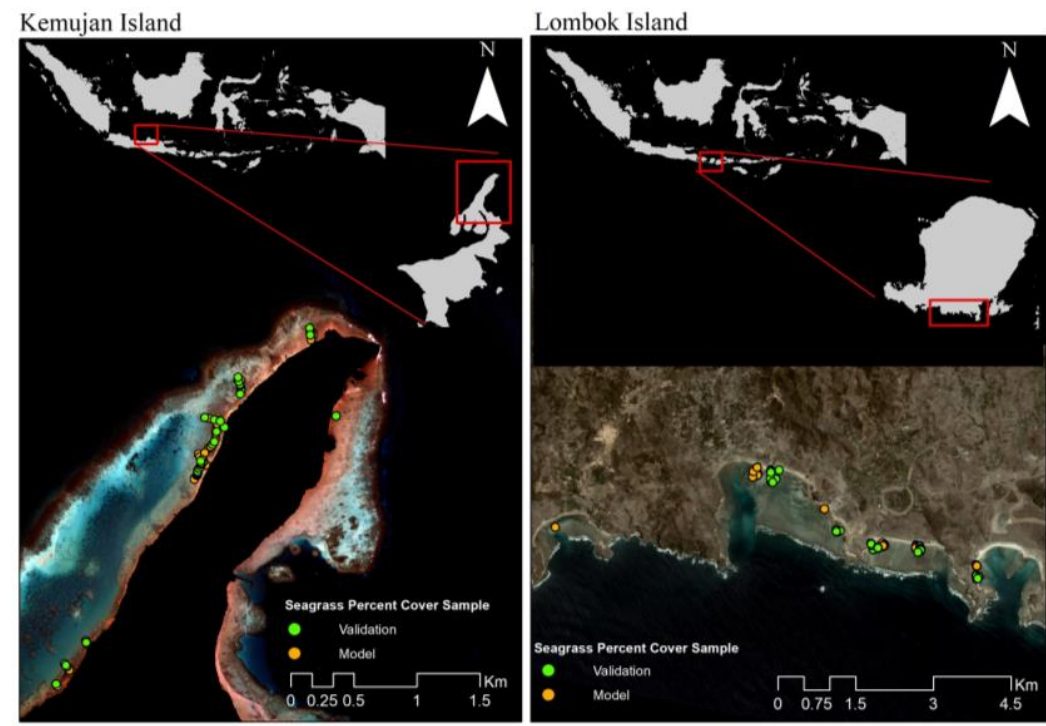
Figure 1. Satellite image of each study area and the spatial distribution of seagrass samples

\subsection{Field data collection}

Seagrass percent cover information was collected in the field using photo-quadrate technique using $1 \mathrm{~m}^{2}$ plot size in the patchy seagrass bed and photo-transect technique (Roelfsema, Phinn, 2010) in the clustered seagrass bed. Seagrass sampling location was determined by considering the variation of seagrass cover as seen from true colour composite of remote sensing image. In both study areas, Enhalus acoroides, Thalassia hemprichii, and Cymodocea rotundata were present. Other species such as Halodule uninervis, Syringodium isoetifolium, and Cymodocea serrulata were only found in Lombok Island. Seagrass coverage was interpreted from the seagrass photo, and each photo was given a UTM coordinate from GPS. DNR Garmin software was used to match the GPS coordinate with the seagrass photo. Percent cover of seagrass was calculated using Coral Point Count Extension for Excel (CPCe 4.0) software using 24 randomly distributed points across the photo. At present study, we did not consider the percentage of seagrass cover for each species found in each photo.

In total, there are 81 seagrass PC samples collected in Kemujan Island, with 46 samples for training area and 35 samples for accuracy assessment. The range of seagrass PC samples in Kemujan Island is $11-100 \%$ with a mean value of $52.43 \%$. In Lombok Island, we collected 139 seagrass PC samples ( 88 for training area and 51 for accuracy assessment), which ranged from $37-100 \%$, with a mean value of $73.95 \%$. The location of seagrass samples collected in the field can be seen in Figure 1. These point samples were converted to raster format at different grid sizes by following the spatial resolution of the original and resampled WorldView-2 and PlanetScope SR image.

The number of seagrass PC samples for image at lower spatial resolution is lesser due to the merging of field data located at similar raster grid. At lower spatial resolution, neighbouring field seagrass samples fell within a single raster grid and the percent cover value for this grid is the average value of seagrass percent cover fell within the grid. For example, if in particular grid there are two seagrass samples at $70 \%$ and $74 \%$ coverage, the grid value will be $72 \%$.

\subsection{Seagrass percent cover mapping}

Seagrass percent cover mapping was carried out using Random Forest (RF) regression (Breiman, 2001), using reflectance values as independent variable and seagrass percent cover collected in the field as dependent variable. The RF regression was conducted for each spatial resolution, and thus, there are five RF model for each study area. For the RF regression algorithm, the number of trees was set to 100 and square root of all features was used as the function to determine the number of randomly selected feature. The RF regression model of seagrass PC only valid for seagrass pixels, hence, pixels other than seagrass were masked out. For Kemujan Island, seagrass mask was adapted from the work of Wicaksono et al. (2019a), while for Lombok Island, seagrass mask was created from visual interpretation based on local knowledge and direct field observation.

Seagrass PC field data for accuracy assessment were used measure the RMS error (RMSE) of the predicted seagrass PC for each spatial resolution. The unit for the RMSE is percent (\%). The evaluation of the resulting map from image at different spatial resolutions was conducted by comparing the RMSE and the spatial distribution of the resulting seagrass PC map, which include the precision and consistency of the result between spatial resolutions.

\section{RESULTS}

\subsection{Seagrass percent cover of Kemujan Island}

The result of seagrass PC mapping in Kemujan Island indicated that the use of $1 \mathrm{~m}^{2}$ field plot size was still effective to train image up to $30 \mathrm{~m}$ despite the patchiness and complexity of seagrass beds. Based on the RMSE, there is no significant difference between the result of image at $2-30 \mathrm{~m}$, where the RMSE difference was only $3.4 \%$. The mean accuracy for all images was $22.06 \%$ with standard deviation $1.32 \%$. Furthermore, the lowest RMSE was obtained using image at $5 \mathrm{~m}$ spatial resolution with $20.95 \%$. The original WorldView-2 image at $2 \mathrm{~m}$ spatial resolution produced slightly lower accuracy with RMSE $21.55 \%$. The summary of seagrass PC accuracy assessment is provided in Table 1.

\begin{tabular}{ccccccc}
\hline & \multicolumn{3}{c}{$\begin{array}{c}\text { Kemujan Island - } \\
\text { WorldView-2 }\end{array}$} & \multicolumn{3}{c}{$\begin{array}{c}\text { Lombok Island - } \\
\text { PlanetScope }\end{array}$} \\
\hline $\begin{array}{c}\text { Spatial } \\
\text { Res. }(\mathrm{m})\end{array}$ & $r$ & $R^{2}$ & RMSE & $r$ & $R^{2}$ & RMSE \\
\hline 2 & 0.31 & 0.10 & 21.55 & 0.66 & 0.44 & 11.20 \\
\hline 5 & 0.29 & 0.09 & 20.95 & 0.68 & 0.46 & 11.04 \\
\hline 10 & 0.17 & 0.03 & 21.87 & 0.63 & 0.40 & 11.93 \\
\hline 15 & 0.00 & 0.00 & 24.35 & 0.62 & 0.38 & 13.20 \\
\hline 30 & 0.39 & 0.15 & 21.58 & -0.13 & 0.02 & 19.20 \\
\hline \multicolumn{4}{c}{ Average } & 22.06 & Average & 13.31 \\
\hline & $\begin{array}{c}\text { Standard } \\
\text { deviation }\end{array}$ & 1.32 & $\begin{array}{c}\text { Standard } \\
\text { deviation }\end{array}$ & 3.39 \\
\hline
\end{tabular}

Table 1. Summary of accuracy assessment of seagrass percent cover mapping at different spatial resolution

Based on the spatial distribution of seagrass PC, the result from $2-10 \mathrm{~m}$ spatial resolution images is very similar (Figure 2 ). The location and variation of different seagrass PC classes is relatively similar, with the main difference is the decreasing precision on image at lower spatial resolutions. At $15 \mathrm{~m}$ spatial resolution, the precision of seagrass PC map starts to diminish. The variation of seagrass with PC at $40-60 \%$ was generalized and dominated by $60-80 \%$ class variation. Nevertheless, the spatial distribution of the remaining $40-60 \%$ class is still similar to the result from $2-10 \mathrm{~m}$. In the $30 \mathrm{~m}$ result, most of the 40 $60 \%$ PC class were missing and the study area is dominated by $60-80 \%$ class. See Table 2 for the area measurement for each percent cover class.

Our result also indicated that seagrass PC is overestimated in the resulting map. This is mainly due to the mixing of seagrass with macroalgae that also has strong absorption in visible bands. Seagrass with low PC but mixed with macroalgae also produced strong absorption, hence low reflectance, in the visible bands compared to when seagrass is mixed with carbonate sand. At coarser spatial resolution, the resampling process also further generalized the seagrass pixels with the surrounding pixels and made the reflectance of seagrass with low seagrass PC lower. This leads to the impression of strong absorption by higher coverage of seagrass PC. In short, for patchy seagrass bed, the RMSE is relatively similar at different spatial resolution, but the precision started to diminish at coarser spatial resolution, possibly at $>10 \mathrm{~m}$, and lower seagrass $\mathrm{PC}$ is overestimated due to the mixing with other benthic habitats. 


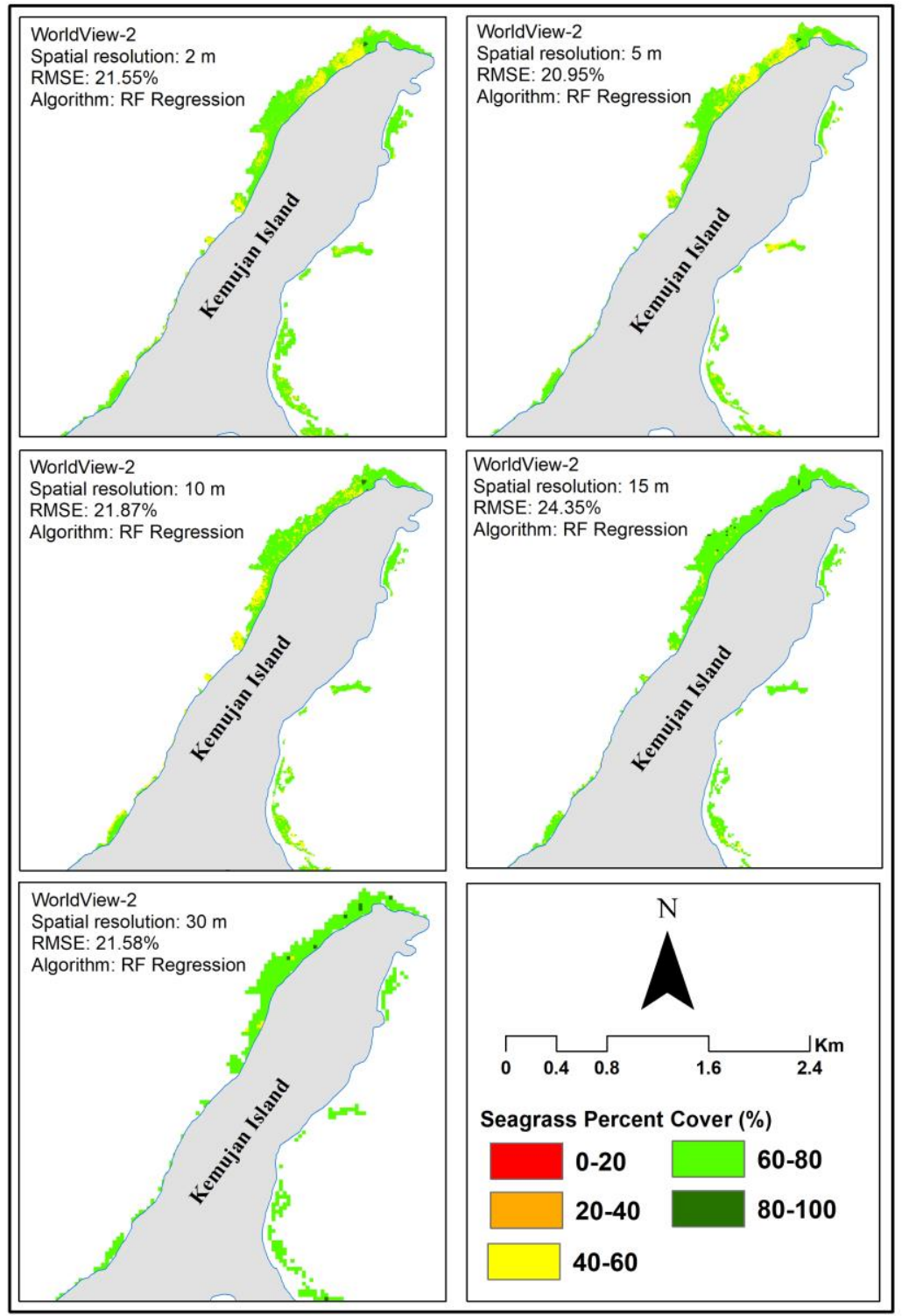

Figure 2. Seagrass percent cover map of Kemujan Island modelled from WorldView-2 image at different spatial resolutions

\subsection{Seagrass percent cover of Lombok Island}

The result of seagrass PC mapping of Lombok Island also indicated the same conclusion. The use of $1 \mathrm{~m}^{2}$ plot size was still effective but only up to $15 \mathrm{~m}$. At $30 \mathrm{~m}$ spatial resolution, the RMSE became much higher. The RMSE of $3-15 \mathrm{~m}$ image is between $11.04-13.20 \%$, while at $30 \mathrm{~m}$ the RMSE rose to $19.2 \%$. The highest accuracy was obtained from $5 \mathrm{~m}$ spatial resolution. The RMSE for Lombok Island is significantly lower than Kemujan Island, which is mainly because the seagrass beds in Lombok Island is continuous and clustered with limited mixing with other benthic habitats. This shows how seagrass bed configuration plays an important role in determining the accuracy of seagrass PC map from remote sensing. PlanetScope image has lower original spatial resolution and has radiometric quality and noise issue when used to map benthic habitat (Wicaksono, Lazuardi, 2018). Meanwhile, WorldView-2 was a consistent performer for mapping benthic habitat (Lyons et al. 2013; Wicaksono et al. 2019b). Nevertheless, PlanetScope produced better accuracy than WorldView-2, which indicated that the seagrass environmental configuration and complexity that determined the accuracy.

\section{Kemujan Island}

\begin{tabular}{cccccc}
\hline \multirow{2}{*}{ PC (\%) } & \multicolumn{5}{c}{ Area (ha) } \\
\cline { 2 - 6 } & $2 \mathrm{~m}$ & $5 \mathrm{~m}$ & $10 \mathrm{~m}$ & $15 \mathrm{~m}$ & $30 \mathrm{~m}$ \\
\hline $40-60$ & 13.35 & 15.45 & 10.77 & 2.26 & 0.72 \\
\hline $60-80$ & 45.01 & 42.95 & 47.67 & 56.35 & 59.85 \\
\hline $80-100$ & 0.12 & 0.11 & 0.18 & 0.29 & 0.81 \\
\hline
\end{tabular}

\section{Lombok Island}

\begin{tabular}{cccccc}
\hline \multirow{2}{*}{ PC (\%) } & \multicolumn{5}{c}{ Area (ha) } \\
\cline { 2 - 6 } & $3 \mathrm{~m}$ & $5 \mathrm{~m}$ & $10 \mathrm{~m}$ & $15 \mathrm{~m}$ & $30 \mathrm{~m}$ \\
\hline $40-60$ & 42.20 & 15.83 & 8.62 & 0.02 & 0.00 \\
\hline $60-80$ & 209.69 & 229.98 & 247.51 & 200.78 & 203.05 \\
\hline $80-100$ & 316.91 & 322.65 & 312.38 & 368.20 & 364.40 \\
\hline
\end{tabular}

Table 2. Area measurement (ha) per seagrass percent cover at different spatial resolution

The spatial distribution of seagrass PC between spatial resolutions also did not vary significantly. The main difference was also the level of information precision, where the variation of seagrass PC at $40-60 \%$ was only visible at $3 \mathrm{~m}$ spatial resolution. Even at $30 \mathrm{~m}$ where the RMSE is much higher than others, the spatial distribution of seagrass $\mathrm{PC}$ is still representative to the overall condition of seagrass $\mathrm{PC}$ in the 
study area. To sum up, for continuous seagrass bed, remote sensing image can produce more accurate result at different spatial resolutions and the use of $1 \mathrm{~m}^{2}$ plot size is also more effective.

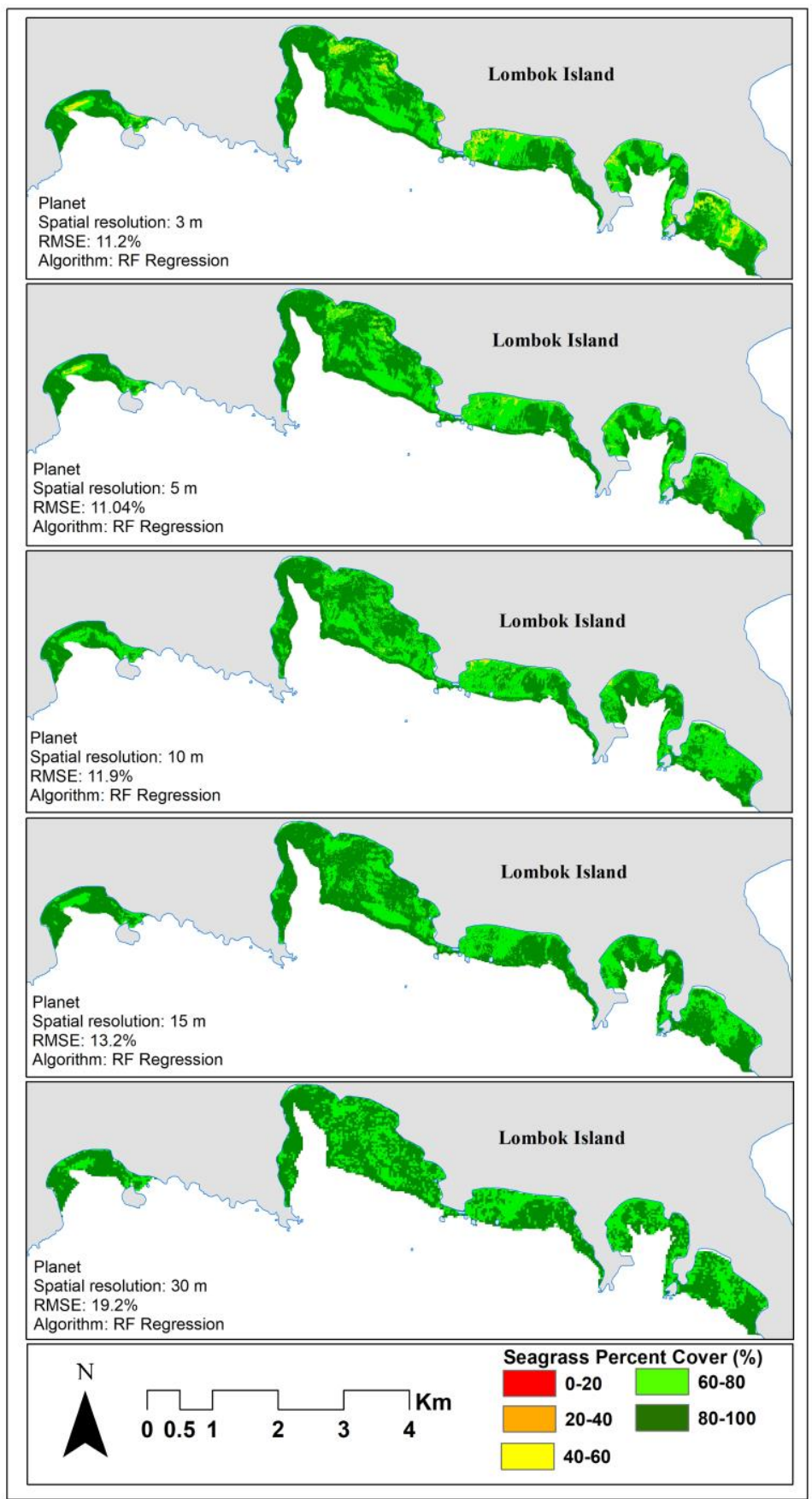

Figure 3. Seagrass PC map from PlanetScope SR image of Lombok Island

\section{DISCUSSION}

The aim of this research is to assess if the use of $1 \mathrm{~m}^{2}$ seagrass PC plot size is effective to train image at different spatial resolutions, from $2-30 \mathrm{~m}$. Our results indicated that its use is still effective up to $30 \mathrm{~m}$ spatial resolution and the mapping results in Kemujan and Lombok Island confirmed this finding. There is no significant accuracy difference between $2-30 \mathrm{~m}$ result in terms of RMSE and the overall spatial distribution of seagrass PC. Indeed, the results from lower spatial resolution image have lesser detail and precision due to the coarser pixel size. Furthermore, what was strongly affecting the accuracy is the configuration of seagrass bed. A more continuous and clustered seagrass bed was mapped more accurately than scattered and patchy seagrass bed. In addition, as the pixel size is getting coarser, pixel mixing become more often and lead to the overestimation of the predicted seagrass PC.

Another interesting result is that the reduced number of samples at lower spatial resolution image due to sample merging technique did not affect the mapping accuracy. This implies that the integration of $1 \mathrm{~m}^{2}$ plot size and mapping accuracy of seagrass $\mathrm{PC}$ is stable at different spatial resolution.

Previous work on mangrove above-ground carbon stock (AGC) mapping also yield similar conclusion where the use of $20 \times 20$ $\mathrm{m}$ field plot size is effective to be integrated with image at $10-$ 
$30 \mathrm{~m}$ spatial resolution and highlighting the importance of collecting representative samples in particular mapping unit that covers all the AGC or other biophysical properties variation in the study area (Wicaksono et al. 2017). In our work, we utilized sample merging technique due to the increase of grid size and this approach worked effectively for all images, and found out that the main factor affecting the success of using smaller plot size sample to train image at lower spatial resolution is the configuration of the seagrass bed.

\section{CONCLUSIONS}

In this research, we managed to draw several important conclusions. First, the use $1 \mathrm{~m}^{2}$ plot size is still effective for image at different spatial resolutions from $2-30 \mathrm{~m}$ with no significant RMSE and overall spatial distribution difference. However, image at lower spatial resolution will have lower precision due to pixel mixing. Second, the difference in the number of samples to model and map seagrass PC did not affect the accuracy. Third, seagrass bed configuration strongly affects the mapping accuracy. More continuous seagrass bed was mapped more accurately than patchy seagrass bed. We will justify this conclusion with future work by using images that has an actual spatial resolution of $5 \mathrm{~m}, 10 \mathrm{~m}, 15 \mathrm{~m}$, and $30 \mathrm{~m}$.

\section{ACKNOWLEDGEMENTS}

This research was funded by Ministry of Research Technology and Higher Education via PDUPT "Penelitian Dasar Unggulan Perguruan Tinggi" Research Scheme Grant No. 2588/UN1.DITLIT/DIT-LIT/LT/2019.

\section{REFERENCES}

Breiman, L., 2001. Random Forests. Machine Learning, 45(1), 5-32.

Costanza, R. R., d'Arge, R., de Groot, R., Farber, S., Grasso, M., Hannon, B., . . . van den Belt, M., 1997. The value of the world's ecosystem services and natural capital. Nature, 387, 253-260.

Hedley, J. D., Harborne, A. R., Mumby, P. J., 2005. Simple and Robust Removal of Sunglint for Mapping Shallow-Water Benthos. International Journal of Remote Sensing, 26(10), 2107-2112.

Hossain, M. S., Bujang, J. S., Zakaria, M. H., Hashim, M., 2015. The application of remote sensing to seagrass ecosystems: an overview and future research prospects. International Journal of Remote Sensing, 36(1), 61-113.

Lyons, M. B., Roelfsema, C. M., Phinn, S. R., 2013. Towards understanding temporal and spatial dynamics of seagrass landscapes using time-series remote sensing. Estuarine, Coastal and Shelf Science, 120, 42-53.

Nordlund, L. M., Koch, E. W., Barbier, E. B., Creed, J. C., 2016. Seagrass Ecosystem Services and Their Variability across Genera and Geographical Regions. PLoS ONE, 11(10), e0163091. doi:10.1371/journal.pone.0163091

Phinn, S. R., Roelfsema, C. M., Brando, V., Anstee, J., 2008. Mapping seagrass species, cover and biomass in shallow waters: An assessment of satellite multi-spectral and airborne hyper- spectral imaging systems in Moreton Bay (Australia). Remote Sensing of Environment, 112, 3413-3425.

Roelfsema, C. M., Lyons, M., Kovacs, E. M., Maxwell, P., Saunders, M. I., Samper-Villarreal, J., Phinn, S. R., 2014. Multi-temporal mapping of seagrass cover, species and biomass: A semi-automated object based image analysis approach. Remote Sensing of Environment, 150, 172-187.

Waycott, M., Duarte, C. M., Carruthers, T. J., Orth, R. J., Dennison, W. C., Olyarnik, S., . . . Williams, S. L., 2009. Accelerating loss of seagrasses across the globe threatens coastal ecosystems. PNAS, 106(30), 12377-12381. doi:10.1073/pnas.0905620106

Wicaksono, P., 2017. Mangrove above-ground carbon stock mapping of multi-resolution passive remote-sensing systems. International Journal of Remote Sensing, 38(6), 1551-1578. doi:10.1080/01431161.2017.1283072

Wicaksono, P., Hafizt, M., 2013. Mapping seagrass from space: Addressing the complexity of seagrass LAI mapping. European Journal of Remote Sensing, 46, 18-39.

Wicaksono, P., Hafizt, M., 2018. Dark Target Effectiveness for Dark-Object Subtraction Atmospheric Correction Method on Mangrove Above-Ground Carbon Stock Mapping. IET Image Processing, 12(4), 582-587. doi:dx.doi.org/10.1049/ietipr.2017.0295

Wicaksono, P., Lazuardi, W., 2018. Assessment of PlanetScope Images for Benthic Habitat and Seagrass Species Mapping in a Complex Optically-Shallow Water Environment. International Journal of Remote Sensing, 39(17), 5739-5765. doi:https://doi.org/10.1080/01431161.2018.1506951

Wicaksono, P., Aryaguna, P. A., Lazuardi, W., 2019. Benthic Habitat Mapping Model and Cross Validation Using MachineLearning Classification Algorithms. Remote Sensing, 11(11), 1279. doi:https://doi.org/10.3390/rs11111279 